Jurnal Teknik Komputer AMIK BSI

Volume 7, No.2, Juli 2021

P-ISSN 2442-2436, E-ISSN: 2550-0120

Akreditasi Ristekdikti, No: 36/E/KPT/2019 (Sinta 4)

DOI: $10.31294 /$ jtk.v4i2

\title{
Penerapan Data Mining Metode K-Means Clustering Untuk Analisa Penjualan Pada Toko Fashion Hijab Banten
}

\author{
Normah $^{1}$, Siti Nurajizah ${ }^{2}$, Arinda Salbinda ${ }^{3}$ \\ ${ }^{1}$ Teknik Informatika, Universitas Nusa Mandiri \\ 1e-mail: normah.nor@nusamandiri.ac.id
}

${ }^{2}$ Sistem Informasi Akuntansi Kampus Kabupaten Karawang, Universitas Bina Sarana Informatika

2e-mail: siti.snz@bsi.ac.id

${ }^{3}$ Sistem Informasi, Sekolah Tinggi Manajemen Informatika dan Komputer Nusa Mandiri

2e-mail:arindasalbinda206@gmail.com

\begin{tabular}{ccc}
\hline Diterima & Direvisi & Disetujui \\
$07-05-2021$ & $08-06-2021$ & $22-06-2021$ \\
\hline
\end{tabular}

\begin{abstract}
Abstrak - Toko Helai merupakan sebuah toko yang bergerak dalam bidang penjualan fashion hijab, namun demikian dari berbagai jenis pakaian yang dijual tentu tidak semuanya yang laris terjual, ada juga yang kurang laris terjual. Data-data penjualan, pembelian barang maupun pengeluaran tidak terduga pada Toko Helai ini tidak tersusun dengan baik, sehingga data tersebut hanya berfungsi sebagai arsip bagi toko dan tidak dapat dimanfaatkan untuk pengembangan strategi pemasaran.Oleh karena itu perlu diterapkan data mining menggunakan metode K-Means pada Toko Helai. Metode K-Means dapat diterapkan pada Toko Helai untuk menentukan penjualan baju mana yang sangat laris, laris dan kurang laris. Penerapan metode K-Means pada toko Helai, yaitu dengan cara mengelompokan data stok baju. Kemudian memilih 3 cluster secara acak sebagai centroid awal. Setelah data pada setiap cluster tidak berubah-ubah, maka dapat diketahui hasil akhirnya yaitu yang sangat laris ada 11 artikel, yang laris ada 55 artikel dan 34 artikel untuk yang kurang laris. Kemudian Menerapkan metode K-Means pada Rapidminer dilakukan dengan memasukkan data stok produk yaitu stok awal, stok terjual dan stok akhir yang akan menjadi Database pada Ms.Excel, data tersebut kemudian dikoneksikan ke dalam Tools Rapidminer, dan akan diolah dan dibentuk K-means. Setelah itu, Rapidminer akan menghasilkan produk mana yang sangat laris, laris, dan kurang laris.
\end{abstract}

Kata Kunci: Data Mining, K-Means, Rapidminer.

Abstract - The Helai store is a shop that specializes in selling hijab clothing, however, of the various types of clothing sold, of course not all are sold, some are not sold well. Data on sales, purchase of goods or unexpected expenses in the shop the hijab is not arranged properly, so that the data only serves as an archive for the store and can not be utilized for the development of marketing strategies. Therefore, it is necessary to apply data mining using the K-Means method of the Hijab shop. The K-Means method can be applied to the hijab shop to determine which clothing sales are best selling, bestselling and not selling. Application of K-Means method at the shop hijab, that is by grouping the stock data. Then select 3 clusters randomly as the initial centroid. After the data on each cluster is not changing, it can be known the end result is a very bestselling 11 articles, the bestselling 55 articles and 34 articles for the less-selling. Then apply the K-Means method on Rapidminer is done by inserting the stock data of the product that is the initial stock, the stock is sold and the final stock will be the Database in Ms. Excel, the data is then connected to Rapidminer Tools, and will be processed and formed Kmeans. After that, Rapidminer will produce the best selling, bestselling, and less-selling products.

Keywords: Data Mining, K-means, Rapidminer.

\section{PENDAHULUAN}

\section{Latar Belakang}

Dalam persaingan dunia bisnis pada saat ini, kita dituntut untuk selalu mengembangkan bisnis agar bertahan dalam persaingan, khususnya dalam persaingan penjualan menuntut para pengusaha untuk menemukan suatu pola yang dapat meningkatkan penjualan dan pemasaran di perusahaan, salah satunya adalah dengan pemanfaatan data penjualan.”.(Siregar, 2018) 
Hal ini tidak dimanfaatkan oleh salah satu toko pakaian yaitu Toko Helai. Toko Helai merupakan sebuah toko yang bergerak dalam bidang penjualan Pakaian Muslimah, namun demikian dari berbagai jenis pakaian yang dijual tentu tidak semuanya yang sangat laris terjual, yang laris, serta kurang laris. Data-data penjualan, pembelian barang maupun pengeluaran tidak terduga pada toko Helai ini tidak tersusun dengan baik, sehingga data tersebut hanya berfungsi sebagai arsip bagi toko dan tidak dapat dimanfaatkan untuk pengembangan strategi pemasaran. Seharusnya data yang telah tersedia dapat dijadikan sebagai sistem pengambilan keputusan untuk solusi bisnis serta dukungan infrastruktur di bidang teknologi yang merupakan penyebab munculnya suatu teknologi yaitu data mining.

Data mining yaitu suatu proses penggalian data data dari sebuah informasi yang sangat penting. Data Mining juga merupakan suatu proses untuk menggali pola-pola dari data. Pola-pola itu didapatkan dari berbagai jenis basis data seperti basis data relasional, data warehouse, data transaksi, dan data berorientasi objek. Penggunaan data mining dapat membantu para pebisnis dalam pengambilan keputusan secara cepat dan tepat(Nurajizah, 2019).

Menentukan pola penjualan dengan melihat kecenderungan pembelian konsumen jika dianalisa dan diolah dengan baik maka dapat membantu mengetahui produk mana yang terlaris dan kurang laku terjual, sehingga kontrol stok persediaan dapat dilakukan, dan dapat dijadikan sebagai masukan bagi perusahaan dalam pengembangkan strategi pemasaran(Normah, Rifai, \& Sari, 2020).

Output Data Mining dapat digunakan untuk membantu pengambilan keputusan di masa mendatang (Normah, Yulianti, et al., 2020). "KMeans ialah metode Clustering non hirarki yang berusaha mempartisi data yang ada ke dalam bentuk satu atau lebih Cluster atau dapat mempunyai tujuan untuk membagi data menjadi beberapa kelompok(Bahar, Pramono, \& Sagala, 2016)". Algoritma k-means untuk mengetahui minat customer terhadap produk yang dijual (Yulianti, Utami, Hikmah, \& Hasan, 2019).

\section{Identifikasi Masalah}

1. Bagaimana cara menerapkan metode Data Mining dengan algoritma K-Means untuk menentukan produk yang sangat laris, laris dan yang kurang laris?

2. Bagaimana cara perusahaan tidak mengalami kesulitan untuk mengelompokkan baju apa saja yang dibutuhkan konsumen dan penyimpanan data-data yang kurang efektif?

\section{Maksud dan Tujuan}

Adapun maksud dari penelitian ini adalah :

Mengimplementasikan konsep data mining menggunakan Algoritma K-Means untuk menentuan produk yang sangat laris, laris dan yang kurang laris sebagai bahan untuk meningkatkan penjualan

Sedangkan tujuan dari penelitian ini adalah membantu Toko Helai dalam menentukan produk penjualan yang termasuk ke dalam kategori sangat laris, laris serta kurang laris.

\section{Maksud dan Tujuan}

1. Observasi

Penulis melakukan pengamatan secara langsung di bagian Penjualan di toko yang beralamat di Cikuya Kecamatan Solear Tangerang Banten.

2. Wawancara

Penulis memperoleh data-data serta meneliti kebenaran informasi data-data tersebut dengan melakukan tanya jawab secara langsung dengan pemilik toko yaitu Ibu Indah.

3. Studi Pustaka

Melakukan studi kepustakaan untuk pengumpulan data dan informasi yang diperoleh dari perpustakaan, jurnal-jurnal, artikel dan internet yang berkaitan dengan penelitian ini.

\section{METODOLOGI PENELITIAN}

Adapun kerangka kerja pada penelitian ini diuraikan sebagai berikut :

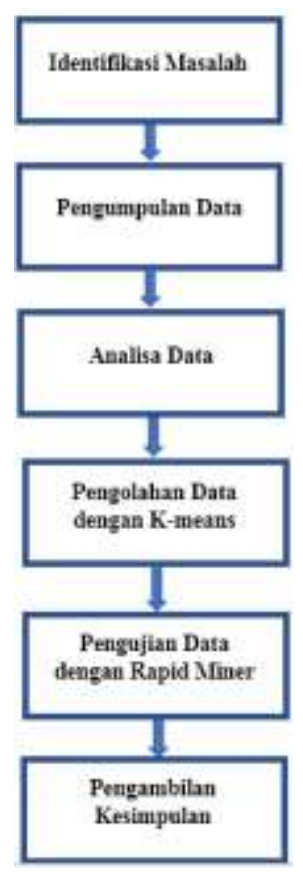

Gambar 1. Kerangka Kerja Penelitian Sumber : Hasil Penelitian (2021) 
Tahapan pada penelitian ini dapat dijelaskan sebagai berikut :

1. Identifikasi Masalah

Yaitu melakukan identifikasi masalah yang terdapat dalam toko yaitu untuk mengetahui produk baju mana saja yang sangat laris, laris, dan kurang laris sebagai acuan strategi persedian stok baju pada toko.

2. Pengumpulan Data

Yaitu mengumpulkan data dengan meminta data stok baju berdasarkan data stok baju periode bulan juli 2019 sampai dengan september 2019 pada toko Helai.

3. Analisa Data

Yaitu menganalisa permasalahan ,yaitu dengan menganalisa data stok baju pada toko Helai.

4. Pengolahan Data

Yaitu dengan mengolah data yang diberikan toko helai, lalu data tersebut diolah dengan metode K-means clustering yang dihitung secara manual untuk mengelompokkan pakaian yang sangat laris, laris dan kurang laris.

5. Pengujian Data

Yaitu dengan melakukan pengujian data yang sudah diolah dengan Rapid Miner.

6. Pengambilan Kesimpulan

Yaitu dengan menarik kesimpulan dari hasil perhitungan dan pengolahan data yang dihitung secara manual dengan data hasil Rapid Miner

\section{HASIL DAN PEMBAHASAN}

Data yang digunakan pada penelitian ini adalah data stok baju pada bulan juli 2019 sampai dengan september 2019 pada toko Helai. Data dibawah ini adalah data yang akan diolah, berupa stok awal, stok terjual dan stok akhir:

Tabel 1. Data Stok Toko helai Bulan Juli 2019 -

\begin{tabular}{clccc}
\multicolumn{4}{c}{ September 2019} \\
\hline No & Artikel & SA & ST & SAK \\
\hline $\mathbf{1}$ & PolyC pink & 54 & 41 & 13 \\
$\mathbf{2}$ & polyC abu & 30 & 25 & 5 \\
$\mathbf{3}$ & PolyC milo & 47 & 40 & 7 \\
$\mathbf{8 6}$ & Kisana & 84 & 63 & 21 \\
& & & & \\
$\mathbf{8 7}$ & Clay Batwing & 34 & 15 & 19 \\
$\mathbf{9 0}$ & Cactus Batwing & 30 & 21 & 9 \\
$\mathbf{9 1}$ & Voal Steelblue & 30 & 17 & 13 \\
$\mathbf{9 2}$ & Catrice Batwing & 33 & 8 & 25 \\
$\mathbf{9 3}$ & Tartan Batwing & 50 & 13 & 37 \\
$\mathbf{9 4}$ & Long Outer & 67 & 29 & 38 \\
$\mathbf{9 5}$ & Najwa Batwing & 44 & 20 & 24 \\
$\mathbf{9 6}$ & Rania Batwing & 50 & 37 & 13 \\
$\mathbf{9 7}$ & Numira Batwing & 36 & 27 & 9 \\
$\mathbf{9 8}$ & Voal Sahara & 20 & 14 & 6 \\
$\mathbf{9 9}$ & Abstak Batik & 25 & 1 & 24 \\
$\mathbf{1 0 0}$ & Grasia & 29 & 7 & 22 \\
& & & & \\
\hline
\end{tabular}

Sumber : Hasil Penelitian (2021)
Langkah-langkah dalam mengcluster menggunakan metode K-Means adalah sebagai berikut :

1. Tentukan nilai $\mathrm{k}$ nya sebagai jumlah klaster yang akan dibentuk.

2. Tentukan Titik pusat awal dari setiap kluster.

3. Hitunglah jarak setiap data input masing masing centroid menggunakan rumus jarak Euclidean (Euclidean Distance) sampai ditemukan jarak yang terdekat dari setiap data dengan centroid.

Berikut adalah persamaan Euclidian Distance :

$D(x, y)=\sqrt{\left(X_{1}-Y_{1}\right)^{2}+\left(X_{2}-Y_{2}\right)^{2}}$

Keterangan;

$\mathrm{D}=$ Jarak

$\mathrm{x}=$ Data

$\mathrm{y}=$ Centroid

4. Mengklasifikasi data berdasarkan kedekatannya dengan centroid.

5. Hitunglah kembali pusat kluster dengan anggota cluster yang sekarang. Pusat cluster ialah nilai rata-rata dari semua data objek dalam cluster tertentu.

6. Hitung lagi setiap objek memakai pusat kluster yang baru. Jika pusat cluster tidak berubah lagi maka proses klustering selesai. Atau, kembali ke langkah nomor 3 sampai pusat kluster tidak berubah lagi.

Tabel 2. Centroid Awal

\begin{tabular}{cccc}
\hline Keterangan & $\begin{array}{c}\text { Stok } \\
\text { Awal }\end{array}$ & $\begin{array}{c}\text { Stok } \\
\text { Terjual }\end{array}$ & $\begin{array}{c}\text { Stok } \\
\text { Akhir }\end{array}$ \\
\hline C1 & $\mathbf{8 4}$ & 63 & 21 \\
C2 & 30 & 18 & 12 \\
C3 & 53 & 33 & 20 \\
\hline
\end{tabular}

Sumber : Hasil Pengolahan Data (2021)

Tabel II adalah Menentukan Pusat Awal Cluster secara acak diambil dari data pada Tabel IV.1. Data yang dipilih untuk cluster awal adalah produk ke-86, 56, 77.

Jarak centroid data ke-1 pada cluster 1 (C1) yaitu:

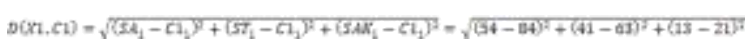

$=900+484+6$

$=38,0525$

Jarak centroid data ke-1 pada cluster 2 (C2) yaitu:

$$
\begin{aligned}
& =576+529+1 \\
& =33,2565
\end{aligned}
$$

Jarak centroid data ke-1 pada cluster 3 (C3) yaitu:

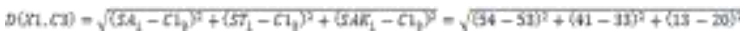

$=1+64+49$

$$
=10,6770
$$


Selanjutnya menghitung centroid baru untuk setiap cluster sesuai data yang tergabung pada setiap clusternya.

Tabel 3. Data Cluster 1 Iterasi 1

\begin{tabular}{lccc}
\hline \multicolumn{1}{c}{ Artikel } & SA & ST & SAK \\
\hline Pashmina pink & 101 & 50 & 51 \\
Pashmina coksu & 96 & 63 & 33 \\
PC black & 104 & 101 & 3 \\
Zahra Black & 112 & 106 & 6 \\
Sabrina Pendek & 64 & 61 & 3 \\
Jasmin White & 100 & 42 & 58 \\
Magnolia & 93 & 73 & 20 \\
Bsc Line Marun & 86 & 55 & 31 \\
Bsc Line Red Velvet & 66 & 64 & 2 \\
Turkishawl Mocca & 90 & 49 & 41 \\
Kisana & 84 & 63 & 21 \\
Jumlah & $\mathbf{9 9 6}$ & $\mathbf{7 2 7}$ & $\mathbf{2 6 9}$ \\
Rata -Rata & $\mathbf{9 0 , 5 4 5 4}$ & $\mathbf{6 6 , 0 9 0}$ & $\mathbf{2 4 , 4 5 4 5}$ \\
\hline
\end{tabular}

Sumber : Hasil Pengolahan Data (2021)

Tabel 3 bahwa cluster 1 pada iterasi pertama menghasilkan 11 data yang tergabung ke dalamnya.

Tabel 4. Data Cluster 2 Iterasi 1

\begin{tabular}{lccc}
\hline \multicolumn{1}{c}{ Artikel } & SA & ST & SAK \\
\hline Polyc Abu & 30 & 25 & 5 \\
Pashmina Green & 35 & 21 & 14 \\
Pashmina Purple & 24 & 23 & 1 \\
Pashmina Milo & 27 & 21 & 6 \\
Pashmina Silver & 33 & 24 & 9 \\
Pashmina & 35 & 31 & 4 \\
Caramel & & & \\
Pashmina Vanilla & 40 & 29 & 11 \\
PC Maroon & 36 & 24 & 12 \\
PC Yellow & 40 & 8 & 32 \\
Lily Hijau & 25 & 23 & 2 \\
Lily Ungu & 25 & 13 & 12 \\
Aisyah Green & 35 & 25 & 10 \\
\hline Sumber:Hasi Pengolat & Data & &
\end{tabular}

Sumber : Hasil Pengolahan Data (2021)

Tabel 4 bahwa Untuk Cluster 2 terdapat 55 data yang tergabung didalamnya.
Tabel 5. Data Cluster 3 Iterasi 1

\begin{tabular}{lccc}
\hline \multicolumn{1}{c}{ Artikel } & SA & ST & SAK \\
\hline Polyc Pink & 54 & 41 & 13 \\
Polyc Milo & 47 & 40 & 7 \\
Polyc Mint & 50 & 34 & 16 \\
Pashmina Peach & 48 & 38 & 10 \\
Pashminabata & 44 & 31 & 13 \\
PC Softblue & 57 & 53 & 4 \\
Lily Pink & 45 & 38 & 7 \\
Isabela Cerut Pink & 44 & 43 & 1 \\
Rajut Skirt Biru & 58 & 45 & 13 \\
Rajut Skirt Black & 67 & 44 & 23 \\
Sabrina Panjang & 50 & 5 & 45 \\
PC Softblue & 57 & 53 & 4 \\
Denim Pants & 60 & 46 & 14 \\
Mocca Pants & 42 & 31 & 11 \\
Cornskin Blue & 56 & 36 & 20 \\
\hline
\end{tabular}

Sumber : Hasil Pengolahan Data (2021)

Tabel 5 bahwa Untuk Cluster 3 terdapat 34 data yang tergabung didalamnya.

Tabel 6. Centroid Baru

\begin{tabular}{cccc}
\hline Ket & SA & ST & SAK \\
\hline C1 & 90,5454545 & 66,091 & 24,45 \\
C2 & 31,0727273 & 19,436 & 11,64 \\
C3 & 51,5 & 33 & 20,18 \\
\hline
\end{tabular}

Sumber : Hasil Pengolahan Data (2021)

Tabel 6 adalah centroid baru yang dihasilkan dari rata-rata dari 3 cluster.

Centroid baru ini dihitung menggunakan rumus sepertirumus iterasi per-1 dan karena tidak ada data yang berpindah cluster dan cluster ke- 1 dan ke-2 hasilnya sama, maka proses perhitungan centroid yang baru dihentikan dan berakhir pada iterasi ke-2. 


\section{K-MEANS PADA RAPIDMINER}

1. Tampilan Hasil Clustering

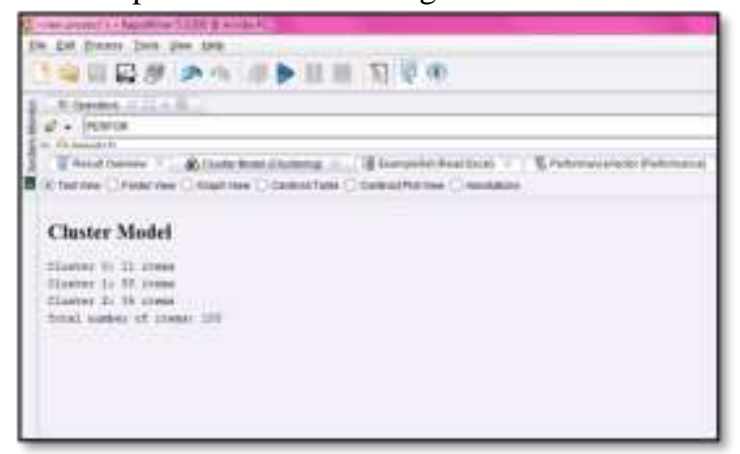

Sumber : Hasil Pengolahan Data (2021)

Gambar 1. Tampilan Hasil Cluster Model

Gambar 1 adalah tampilan hasil cluster model dari data yang diolah.

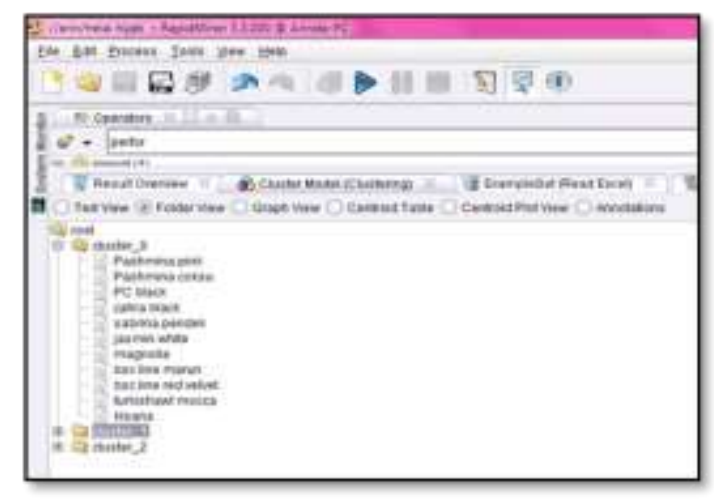

Sumber : Hasil Pengolahan Data (2021)

Gambar 2. Tampilan Hasil Cluster 1

Gambar 2 adalah tampilan hasil cluser 1 yang sudah diolah dari Rapidminer.

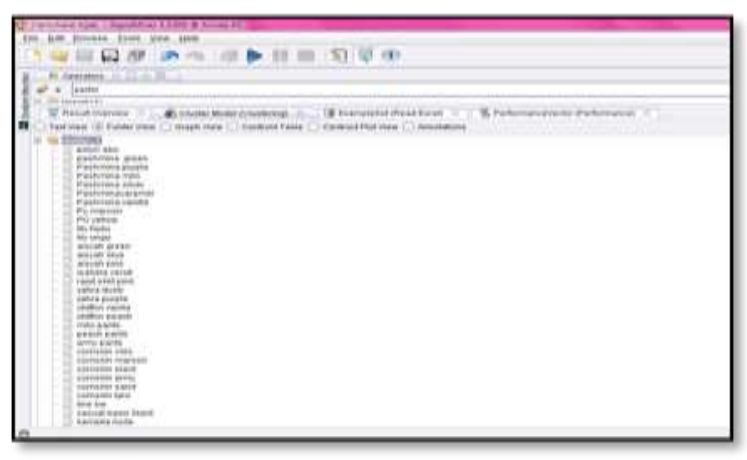

Sumber : Hasil Pengolahan Data (2021)

Gambar 3. Tampilan Hasil Cluster 2

Gambar 3 adalah tampilan hasil dari cluster 2 yang sudah diolah dari Rapidminer.

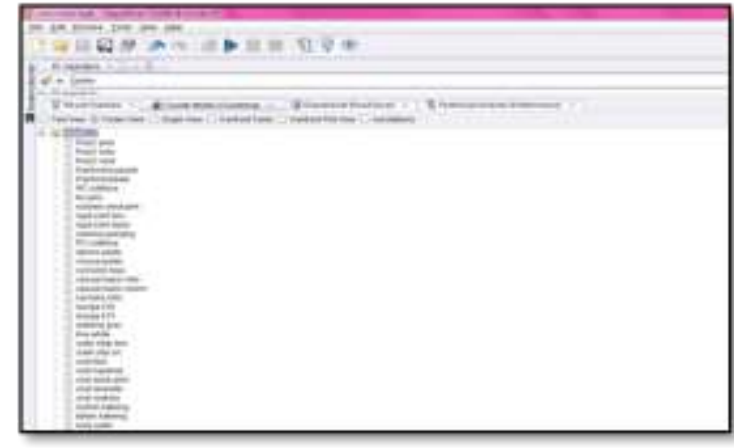

Sumber : Hasil Pengolahan Data (2021)

Gambar 4. Tampilan Hasil Cluser 3

Gambar 4 adalah tampilan hasil dari cluster 3 yang sudah diolah dari Rapidminer.

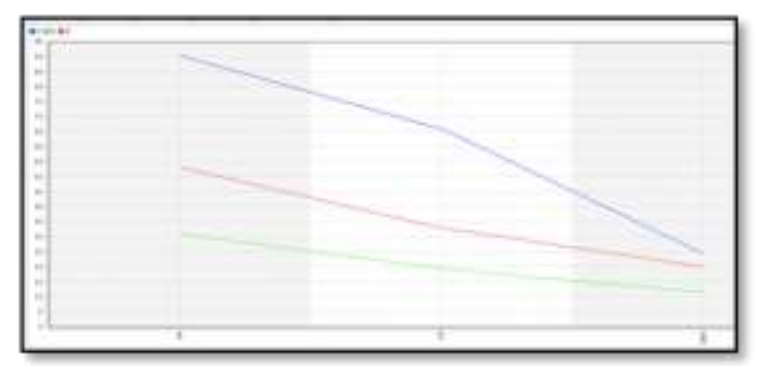

Sumber : Hasil Pengolahan Data (2021)

Gambar 5. Hasil Pengolahan Data Pada Rapidminer Gambar 5 merupakan hasil pengolahan data pada Rapidminer yang ditandai dengan warna biru merupakan hasil dari cluster 1, warna hijau adalah hasil dari cluster 2 dan warna merah merupakan hasil dari cluster 3 .

\section{KESIMPULAN}

1. Metode K-means dapat diterapkan pada toko Helai untuk menentukan penjualan baju mana yang sangat laris, laris dan kurang laris. Penerapan metode K-Means pada toko Helai, yaitu dengan cara mengelompokan data stok baju. Kemudian memilih 3 cluster secara acak sebagai centroid awal. Setelah data pada setiap cluster tidak berubah-ubah, maka dapat diketahui hasil akhirnya yaitu yang sangat laris ada 11 artikel, yang laris ada 55 artikel dan 34 artikel untuk yang kurang laris.

2. Metode Data Mining menggunakan K-Means sangat membantu dan mempermudah toko Helai untuk mengembangkan strategi persediaan stok baju .

3. Menerapkan metode $K$-means pada Rapidminer dilakukan dengan memasukkan data stok produk yaitu stok awal, stok terjual dan stok akhir yang akan menjadi Database pada Ms.Excel, data tersebut kemudian dikoneksikan ke dalam Tools Rapidminer, dan akan diolah dan dibentuk K-means. Setelah itu, 
Rapidminer akan menghasilkan produk mana yang sangat laris, laris, dan kurang laris.

\section{REFERENSI}

Bahar, A., Pramono, B., \& Sagala, L. H. S. (2016). Penentuan strategi penjualan alat-alat tattoo di studio sonyxtattoo menggunakan metode. SemanTIK, 2(2), 75-86.

Normah, N., Rifai, B., \& Sari, P. (2020). Algoritma Apriori Sebagai Solusi Kontrol Persediaan Suku Cadang Mobil PT. Buanasakti Aneka Motor Jakarta. Paradigma - Jurnal Komputer Dan Informatika, 22(2), 161-168. https://doi.org/10.31294/p.v22i2.6530

Normah, Yulianti, I., Novianti, D., Winnarto, M. N., Zumarniansyah, A., \& Linawati, S. (2020). Comparison of Classification C4.5 Algorithms and Naïve Bayes Classifier in Determining Merchant Acceptance on Sponsorship Program. Journal of Physics: Conference
Series, 1641(1). https://doi.org/10.1088/17426596/1641/1/012006

Nurajizah, S. (2019). Analisa Transaksi Penjualan Obat menggunakan Algoritma Apriori. INOVTEK, 4(1), 35-44.

Siregar, M. H. (2018). Data Mining Klasterisasi Penjualan Alat-Alat Bangunan Menggunakan Metode K-Means (Studi Kasus Di Toko Adi Bangunan). Jurnal Teknologi Dan Open Source, 1(2), 83-91. https://doi.org/10.36378/jtos.v1i2.24

Yulianti, Y., Utami, D. Y., Hikmah, N., \& Hasan, F. N. (2019). Penerapan Data Mining Menggunakan Algoritma K-Means Untuk Mengetahui Minat Customer Di Toko Hijab. Jurnal Pilar Nusa Mandiri, 15(2), 241-246. https://doi.org/10.33480/pilar.v15i2.650 